\title{
FGFR2 NM_000141.4:C.1645A>C
}

National Cancer Institute

\section{Source}

National Cancer Institute. FGFR2 NM 000141.4:C.1645A>C. NCI Thesaurus. Code C107603.

A nucleotide substitution at position 1645 of the coding sequence of the FGFR2 gene where cytosine has been mutated to guanine. 